\title{
Circumstances leading to self-diagnosis and self- medication in the Municipality of Marabá (State of Pará, Brazil)
}

\section{Amanda Neves da Silva ${ }^{1}$, Carlos Eduardo Brito Cavalcante ${ }^{\mathbf{1}}$, Jobson dos Anjos Ferreira ${ }^{1}$ and Daniela Soares Leite ${ }^{2}$}

${ }^{1}$ Universidade do Estado do Pará - UEPA. Curso de Biomedicina. Centro de Ciências Biológicas e da Saúde. Campus VIII. Avenida Hiléia, S/№. Agrópolis do Incra. Bairro Amapá. Marabá-PA, Brazil. (CEP 68502-100).

${ }^{2}$ Universidade do Estado do Pará - UEPA. Centro de Ciências Biológicas e da Saúde. Campus VIII. Departamento de Morfologia e Ciências Fisiológicas. Avenida Hiléia, S/№. Agrópolis do Incra. Bairro Amapá. Marabá-PA, Brazil. (CEP 68502-100). Email: danielaleite@uol.com.br.

\begin{abstract}
The theme medication/self-diagnosis presents contrary opinions about what is right or wrong, in addition to being scarce the quantitative studies with the purpose to clarify the causes of these two dangerous practices. For both, the objective of this study was to identify the causes that influence the self-diagnosis and medication, as well as analyze failures in public assistance in health, which can be promoting the avoidance of the patient to search for an alternative medicine, evidencing the risk that this done can promote. It was a descriptive and cross-sectional study, of qualitative nature, carried out in all health centers in the urban area of Marabá (Pará State, Brazil), through the application of forms and having the data analyzed and tabulated, making use mainly of Chi-square statistical test. The results showed that education is not directly related to the medication, which before was vacant in literature, but the main result highlighted expressed that the motivation for the choice of ingesting medication without prescription, are the difficulties encountered in SUS, the poor quality of care and failures in the relationship doctor patient of the public health service.
\end{abstract}

Keywords: Self-medication; Self-diagnosis; Medical anthropology.
Received

April 11, 2018

Accepted

April 28, 2018

Released

April 30, 2018

Full Text Article

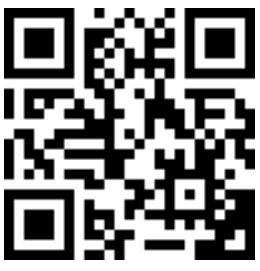

ORCID

(1) 0000-0003-0136-0561

Amanda Neves da Silva

(1) 0000-0001-5000-2635

Carlos Eduardo Brito

Cavalcante

(1) 0000-0003-0949-752X

Jobson dos Anjos

Ferreira

(D) 0000-0002-3412-1375

Daniela Soares Leite 


\section{Introduction}

The reflection on the medication and the self-diagnosis in actuality, presents a polarity of opinions in relation to what is considered correct and incorrect in applying these, because if debate that a certain level of medication would be desirable, because it would contribute to reduce unnecessary utilization of health services. However, this issue involves variables, such as the cultural process, use of new technologies for self-care, socio-economic issues, age, and even influenced by the doctorpatient relationship in public health care, in this way, the decision to take a medicine from the palm of your hand to your stomach is unique to the patient, has a responsibility to do it depends on whether or not support given by the opinion of the physician or other health care professional (Automedicação, 2001).

Alternative medicine, according to Luz (2005), refers to a practice that are technologically deprived of medicine, coupled to a set of traditional medical knowledge, and this has been culturally passed down through the generations. The higher the level of complexity of a society, greater variety of alternative therapies, but for the sick person, the origin of the treatments has less importance than the effectiveness in alleviate the suffering (Helman, 2009). The vulgar or popular knowledge, however, has generated trust surplus to the people, creating risks for the freedom to self-medicate.

The mass media, are refreshed on a daily basis a concept directly connected to the logic of self-accountability in health - the individual empowerment in the belief that, by way of consumerism, the sum of our individual health if paid to the promotion of a healthy society. Combined with the provision of technical information on the internet, have also foreshadowed the emergence of a new public health, based on self-clarification and selfresponsibility the users on issues related to their health inducing them to self-test. The practice of self-medication, described by the National Sanitary Surveillance Agency (ANVISA) and the Ministry of Health (MS) as being the use of medication without a prescription, orientation and/or monitoring of the doctor or dentist, although together with the diagnosis by means of information of the type "ask the doctor", disseminated via e-mail messages without identification, has demonstrated a wide range and are efficient as a complementation of the classic forms of assistance, they still show limited as to be able to identify the distance diseases showing great inadequacy of information to the realities of the users. Even so, the self-diagnosis and self-medication go beyond quick and easy access to information, because corroborate with the practice of self (Vasconcellos-Silva and Castiel, 2009).

The doctor-patient relationship and the quality of care from public health issues are discussed in view of the fact that the anamnesis and the dialog between the patient and the doctor has been an efficient framework for the diagnosis of the disease and to the patient confidence in following the treatment correctly. With the emergence of new technologies and complementary examinations, which gave a greater efficiency in diagnosing this doctorpatient relationship was being set aside, hence the increase in the number of patients complainants about the failure in dialog with physicians has grown, such as lack of confidence in the treatment indicated (Rocha et al., 2011). The Ministry of Health (MS) in line with the World Health Organization (WHO), for example, values features and methods biomedical not relating to the health/disease process/cure, in the expectation that manifest small networks 
agglutinated universal and integral care, based on physician-patient relations alternatives, to complement the service provided in public health care in health (Andrade and Costa, 2010).

The context in which we live the Single Health System (SUS) currently, is too separate from the time that precedes the establishment of SUS, where in truth, was not recognized the right to health of Brazilians in all instances and specialties. The evolution of the healthcare system, triggered financial problems, managerial and organizational factors that trigger the deployment of the principles of the SUS so fast, bringing difficulties in ensuring equity and comprehensiveness governing principles of the Single Health System (Furlan, 2011). In short, the difficulty of access to health services and the increase in the cost of medicines encourages the demand for alternative forms of treatment, such as medicine or natural healing, religious, popular and cultural knowledge, increasing the incidence of medication and contributing to the increase of the crisis of the Single Health System (Ascari et al., 2014).

According to the Ministry of Health, the association between the use of antimicrobials and the development of bacterial resistance began to be highlighted after the launch of various representatives from each of the different pharmacological classes, being that the period necessary for the occurrence of this phenomenon was surprisingly short for many drugs, mainly from the $\beta$-lactam class. Although these observations should submit an alert signal for the need for rational use of these medicines, what has occurred, in fact, is exactly the opposite (Brazil, 2012).

The use of non-steroidal is properly marked, according to the Gazeta Mercantil (2008), the antiinflammatories became over time, the medicine of routine for the fight of inflammation and pain by providing an immediate relief. Any type of inflammation, muscle tension, torticollis is a reason for that person to drive the pharmacy behind an anti-inflammatory activity. These drugs are sold without a prescription without any control of the competent health authorities, being that the medication and the abuse of nonsteroidal anti-inflammatory steroids usually affect the gastric mucosa (Lima and Neto Filho, 2010).

The use of analgesics also has been a major focus of the medication. According to Melo (2007), cited by Pieper (2013), stated that in his study, 22,165 cases of drug intoxications registered by six Poison Control Centers, $2,263(10.21 \%)$ were for medications (anodynes dipyrone, salicylates and paracetamol), so may realize that the medicines free sale between them painkillers that many times the population think they are exempt from risks are those that most often cause complications for health (Pieper et al., 2013).

The fact of being scarce the quantitative studies with the purpose to clarify the circumstantial causes of selfdiagnosis and self-medication, allied to the motivation of these practices under the perspectives of classical texts of strategies of inclusion, create a scenario, in short, neglected, that jumps to the views of health professionals and has little reaction in order to reverse this condition. That said, further studies are necessary to suggest the motivation of deviations from the traditional medical treatment and the negative consequences of self-medication and self-diagnosis, knowing the main types of medications used by these individuals, with the aim to raise awareness about the risks that this action can promote.

Based on these arguments, the objective of this study was to identify the causes that influence the practice of selfdiagnosis and self-medication, prevalent in the municipality of Marabá (PA), as well as analyze failures in public assistance in health, which can be promoting the avoidance of the patient to search for an alternative medicine. 


\section{Methods}

The present study was a descriptive and cross-sectional study, of qualitative nature, having as places of research 12 health centers in the urban area of Marabá, with prior knowledge of the Municipal Secretariat of Health of the Municipality of Marabá (Pará State), and portraying how the research participants, users of the Single Health System who attend the health units of the municipality, in the year 2017.

For inclusion criterion, in this study, we adopted the application forms for users of health centers in the urban area of Marabá, with age greater than or equal to 18 years, of both sexes, literate and intellectual capacity preserved, and for exclusion criteria were considered users of the health plan or private care services, aged less than 18 years, and users are illiterate and/or psychological disorder/disability that prevented the consent of the Free and Informed Consent Term (TCLE).

The data collection was carried out through the application form, composed of 16 questions related to the theme, which were answered by users of health centers of the urban perimeter.

The research participants were users of the Single Health System who attend, routinely, the health units referred to above. The sample size calculation was performed using a probabilistic sample analysis for the Municipality of Marabá/PA, with a confidence level of $95 \%$ and a sampling error of $5 \%$, for one. Within this perspective, obtained a total sample of 384 users of SUS, stratified into 32 forms in each health unit.

The research was carried out through the application forms, which were directed questions about the use of cultural knowledge, research on health on the internet, and traditional medicine, as a source of information for the selfdiagnosis and self-medication, as well as the quality of public assistance in health. Also included with individual information of each researched (age and education), as well as what the drug most often used without medical prescription and the reason for this choice.

The questions were read and directed to the researched, being clarified doubts regarding the spelling or meaning, when necessary. The researchers took care regarding the treatment of data and privacy of the information provided by the participants.

Used the software Microsoft Office Excel 2016(C), by the fact that a descriptive analysis of quantitative variables, for tabulation and graphics data, as well as the ratio of the data obtained for one of the variables investigated in the research problem presented, the medication; in addition to the program Bioestat(C), in its version 5.3, for analysis and significance of the correlation of the variables of the study. The Chi-square test was used (contingency table) to compare proportions, i.e., the possible differences between the observed and expected frequencies for an event. If you have applied the test of binomial probability distribution.

The realization of this study followed the precepts of the Declaration of Helsinki and Nuremberg Code, as well as the Resolution No. 466/2012, of the National Health Council (Brasil, 2012). The study was conducted after submission and approval by the Committee for Ethics and Research with Humans UEPA, under the case 65665317.8.0000.5174 and ethics committee opinion, No. 1965333. All participants read and signed an Informed Consent Form, these being instructed and advised at all points of the research, always guaranteeing the safety and rights of the research subject.

\section{Results and discussion}

The results in Table 1 show that the number of patients who do not trust always in the diagnosis given by the doctor, was 198 (51.56\%), and the plot 
of 241 (62.76\%), patients who replied that they go to the doctor is not the first choice when you are sick. The response of the patients claiming to have a good talk with your doctor about what you're feeling to be consulted, had not expected value of $243(63.28 \%)$, characterizing a probable random error.

Table 1. Doctor-patient relationship from the results of three related issues.

\begin{tabular}{ccc}
\hline Doctor-Patient Relationship & $\mathbf{N}$ & $\mathbf{\%}$ \\
\hline Go to the doctor is your first choice when you are sick? & & \\
\hline Yes & 143 & $37.23 \%$ \\
Do not & 241 & $62.76 \%^{*}$ \\
\hline When it is consulted, you have a good conversation with & & \\
Your doctor about what you're feeling? & & \\
Yes & 243 & $63.28 \%^{*}$ \\
Do not & 141 & $36.71 \%$ \\
\hline You trust always in the diagnosis of doctor? & 186 & $48.43 \%$ \\
Yes & 198 & $51.56 \%^{*}$ \\
\hline Do not
\end{tabular}

*Has a statistical significance $(\mathrm{p}<0.05)$.

The results pertinent to the doctor-patient relationship refers to a failure in this question. The majority $(62.76 \%)$ did not have as first option the demand for medical care, as well as $51.56 \%$ do not trust always in the diagnosis given by the doctor. This effect is consistent with another study found. It is possible to have a perception of apparent cause for this lack of confidence of the patient to the doctor, tending to seek another form of diagnosis and cure, Caprara and Rodrigues (2004), presented a study in which $50 \%$ of consultations, doctors and patients do not agree on the nature of the main problem and $65 \%$ of the patients are interrupted by doctors after 15 seconds of explanation of the problem.

The type of physician-patient relationship from the classification of Robert Veatch, the Kennedy Institute of Ethics of Georgetown University, cited by Rocha et al. (2011), which fits in the results is the model for priests, as was already expected before the study, which suggests the complete submission of the patient to the doctor, does not value the culture and beliefs of the patient, with little involvement and the decision is made only by the doctor.

A result not expected and incompatible with the results obtained in the literature, was the number of patients who reported having a good talk with your doctor about what feels (63.28\%). This phenomenon may have occurred due to poor understanding of the question or in spite of the patient to achieve, in fact have a good dialog with the doctor about what you're feeling, the professional may be suppressing the consideration of some factors, psychological and/or cultural, which may decrease the patient trust by the physician.

The opinion of the participants of this study on the risks that the medication may cause ("Do you think that the medication can bring some risk to health?"), is expressed in Figure 1, in which 357 (92.96\%) of these attested that yes, the medication can bring risks to health and only 27 (7.03\%) claimed the opposite. 


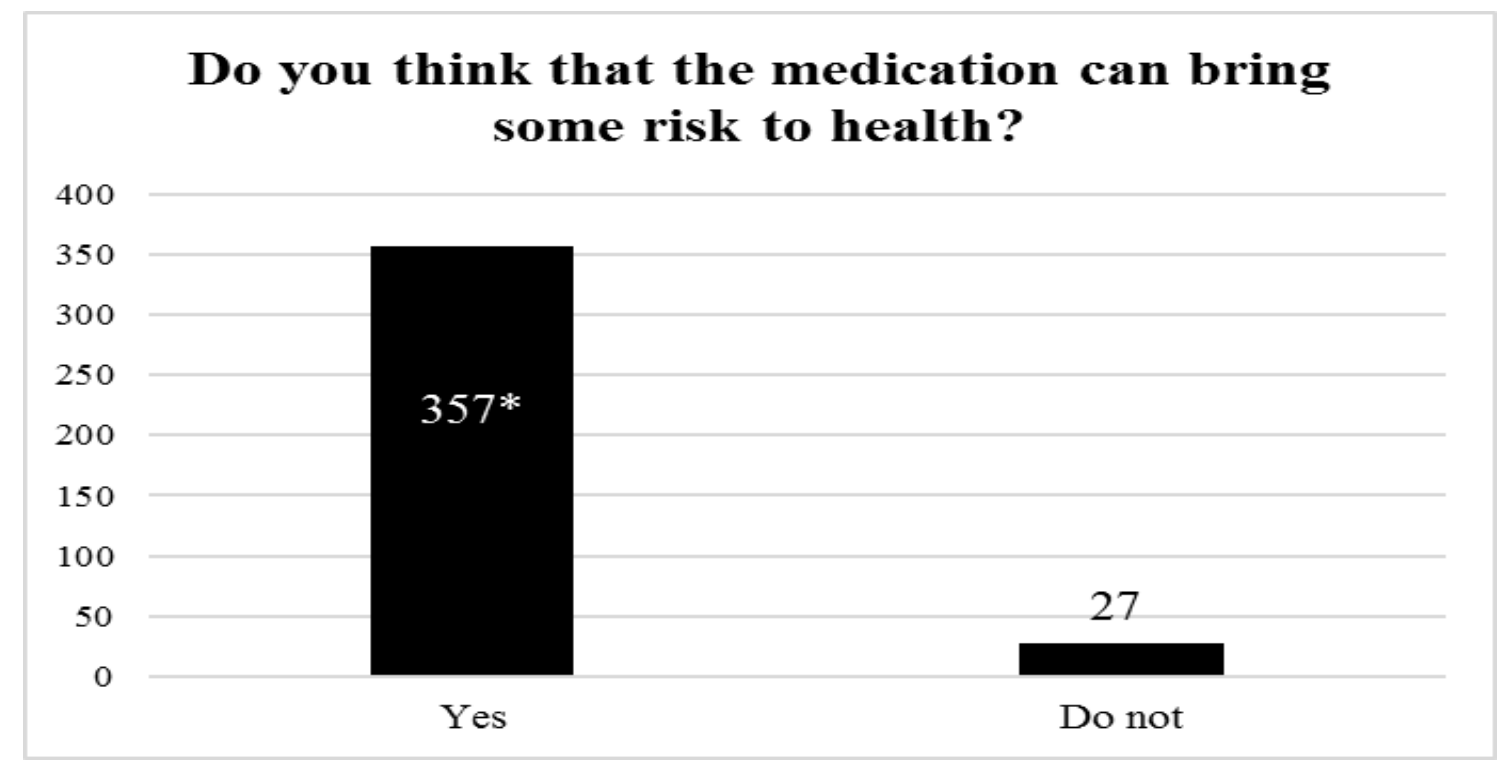

Figure 1. Feedback from participants about the consequences of medication for health. *Has a statistical significance $(\mathrm{p}<0.05)$.

The variable quality of the public health service, as well as the conclusion that the difficulties encountered in the public health system can be associated with self-medication and self-diagnostic, are shown in Figure 1, and on the form was represented by the question "Do you think that the difficulties encountered in the public health system influence the type of diagnosis and treatment that you will choose", in which 341 people (88.8\%) believe that the difficulties of SUS may influence the choice of treatment used and only 43 (11.19\%) disagree with this theory.

When dealing with a particular view of the participants of this research, if the medication could result in risks to health, 92.96\% answered "yes", being inconsistent with the amount of individuals who responded had already if self-medicated $(90.10 \%)$, this event refers to a possible lack of medication among the participants and the population in general. It is understood that medication is solely the ingestion of prescription drugs (red or black stripe) without the indication of a doctor, not including non-prescription medicines or natural remedies. Another explanation for this result is that even patients knowing the concept of self-medication and the risks that this practice can promote, prefer to medicate to achieve a medical indication. This second observation is more consistent with the results found, already mentioned, such as the question of why the participants if self-medicate, where the greatest number of 178 (46.35\%) replied that the reason was the difficulty in achieving public health care. In this way, participants assume the risk of medication.

The results of the questioning about the causes more applicants medication ("Why Do You selfmedicate?"), are shown in Figure 2, presenting $27(7.03 \%)$ for participants that if self- medicate influenced by family members, $41(10.67 \%)$ because they do not like to go to the doctor, 178 (46.35\%) have difficulty in achieving public health care, 75 (19.53\%), if self- medicate per usual and $63(16.40 \%)$ claim does not make medication. 


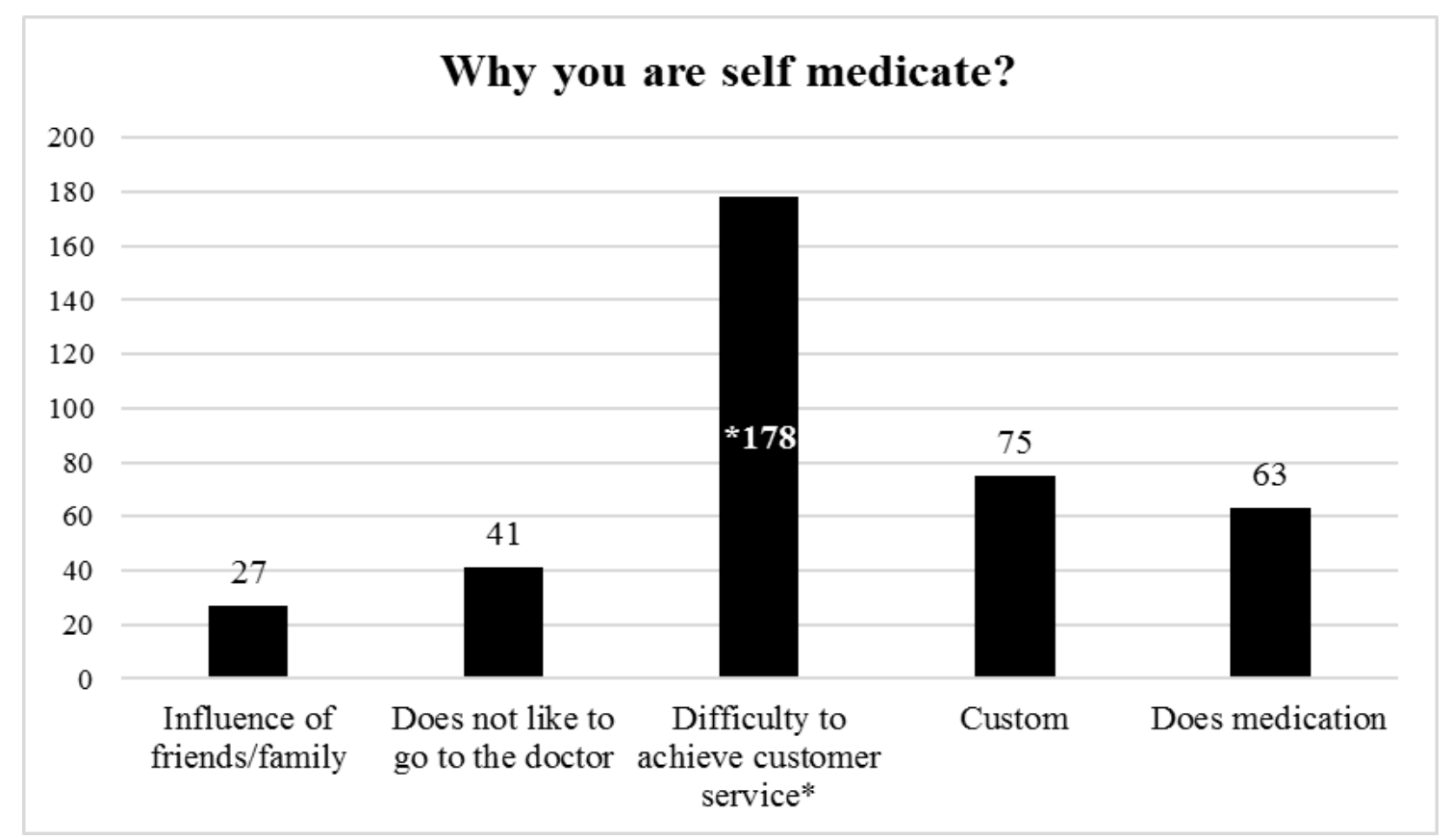

Figure 2. Causes more applicants of the medication. ${ }^{*}$ Has a statistical significance $(\mathrm{p}<0.05)$.

The main circumstantial causes present that lead to self-diagnostic and medication, the main objective of this work was widely clarified the results displayed in Figures 2 and 3, highlighting the difficulty of patients in obtaining care and have the same with quality. The question whether the difiuldades found in the public health system influence the type of treatment you choose, $88.8 \%$ of the participants answered "yes", demonstrating the relationship that the flaws in the Single Health System, leading to the medication.

Wood (2013) base best this argument by saying that along the trajectory of the SUS, were built negative images on public assistance, which serve as criteria for evaluation of the effectiveness of the public system. Bad conditions of primary care to the population health, entrance door to SUS, is also described by the lack of medical equipment, laboratory examination and even basic medicines for diabetes, hypertension, anthelmintic or antibiotics. Without the necessary medicines, patients are at the mercy of indications family, friends, or for purchase of medicines.

It is consider, even so, the statements of Menicucci (2006), that the negative images of SUS arise through lack of quality and efficiency in customer service, giving rise to a growth as the brain of patients for other types of care for diagnosis, he being private, not traditional, or your own self-diagnostic. And the author concludes: "The system is still inadequate for the needs of the assisted population". 


\section{Do you think that the difficulties encountered in the public health system influence the type of treatment you will choose?}

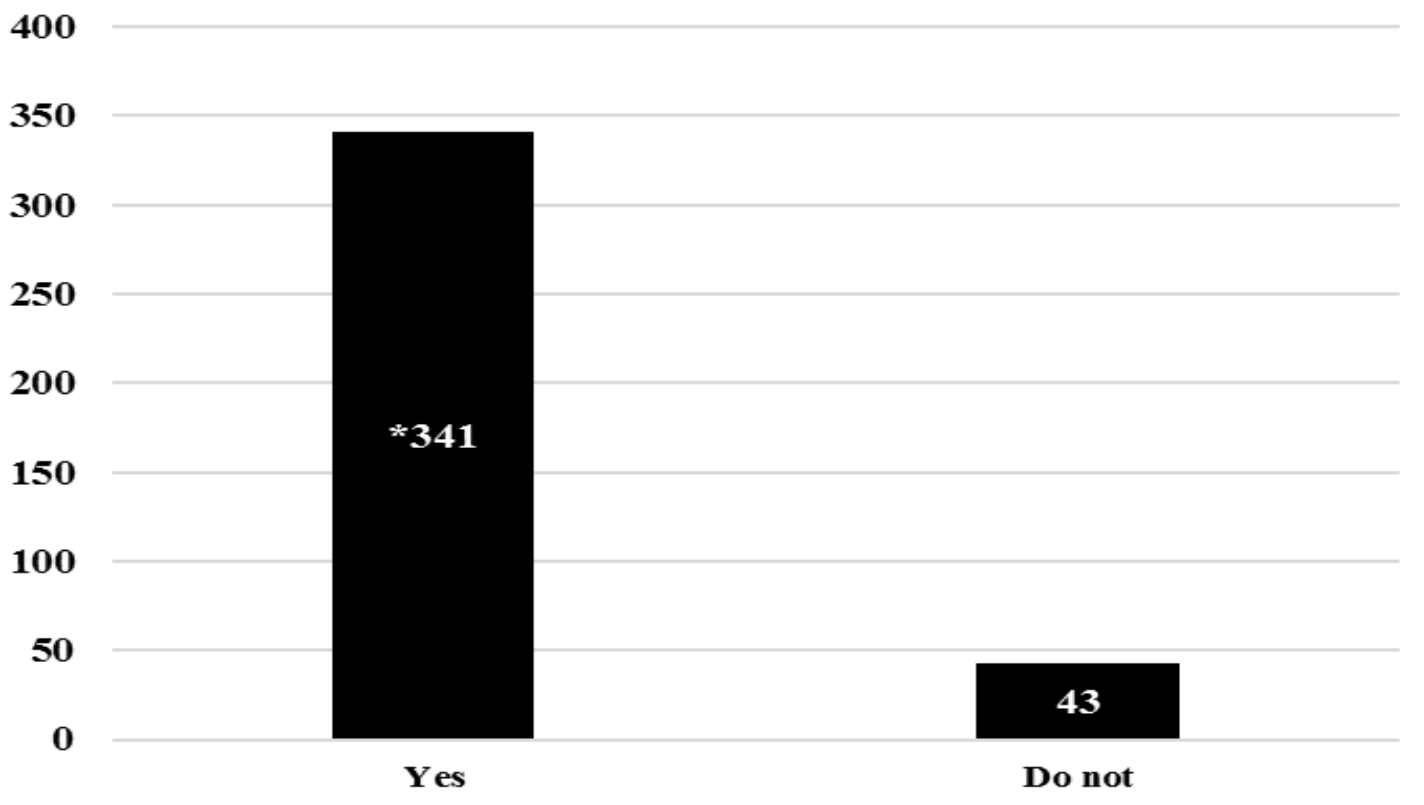

Figure 3. Influence the quality of the public health service in self-medication. *Has a statistical significance $(\mathrm{p}<0.05)$.

The literature presented interesting data in the study of the relationship of the degree of schooling with medication, which similarly agreed with the results of this research, highlighted in Figure 4, where, the degree of schooling found in this study presented values of $45 \quad(11.71 \%)$ participants with complete Basic Education, 88 (22.91\%) with incomplete basic education, 111 (28.90\%) with complete secondary education, 72 (18.75\%), with incomplete secondary education, 29 with complete higher education (7.55\%) and $39(10.15 \%)$ with incomplete higher education.

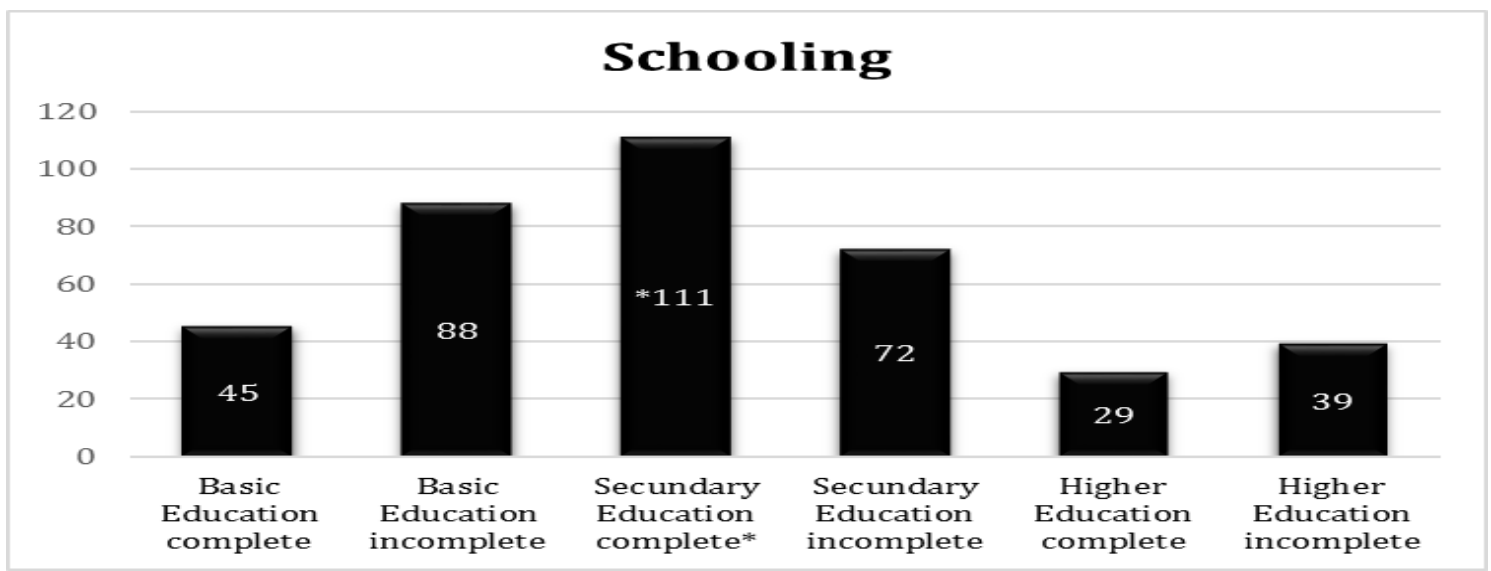

Figure 4. Degree of schooling of the participants. ${ }^{*}$ Has a statistical significance $(p<0.05)$. 
In the study by Pinheiro et al. (2013), contrary to expectations, the greater prevalence of use of medicines not prescribed occurs in individuals with higher schooling, as presented in this study, where 111 (28.90\%) participants have complete secondary education. Pinheiro et al. (2013) explains this situation reported that individuals with complete higher education have greater contact with the system of private health insurance and/or greater involvement in therapeutic decisions in advance, which makes them able to feel safe to medicate, however, the study was an exclusion criterion, individuals who have private health insurance, leaving the possibility of this result be interpreted due to the few studies about medication that include the population of high income and schooling.

The results on the most frequently used type of medication, as well as the symptoms by which they are used and their efficacy, represented by the questions on the form "What drug do you use most often?", "What are the most frequent symptoms you use medicines" and "Does the medication used always work against the symptoms?"), are shown in Table 2, revealing that 56 $(14.58 \%)$ of the participants used antibiotics more frequently, 122 (31.77\%) used anti-inflammatories, 181 (47.13\%) used analgesics and 25 $(6.51 \%)$ did not opt for any of the previous alternatives.

As for the most common symptoms, in which the participants used medications, 152 (39.58\%) reported headache, 114 (29.68\%) muscular pain, $28(7.29 \%)$ stomach pain, $6(1.56 \%)$ responded nausea, 12 (3.12\%) allergies and $49(12.76 \%)$ responded to influenza and cold.

When asked whether these same drugs were effective against the symptoms $243(63.28 \%)$ reported that yes, $6(1.56 \%)$ said no and 135 (35.15\%) answered that only sometimes the drugs work against the symptoms. This event can be explained by the misuse of a particular medication for the symptoms.

During the application of the forms, it was common to hear phrases like "When these other remedies for the flu does not work there, I have to buy antibiotics", or "I use anti-inflammatory drugs.

Table 2. Medication issues.

\begin{tabular}{ccc}
\hline Which medicine do you use most often? & $\mathbf{N}$ & $\mathbf{\%}$ \\
Antibiotic & 56 & $14,58 \%$ \\
Anti-inflammatory & 122 & $31,77 \%$ \\
Analgesic & $181^{*}$ & $47,13 \%$ \\
No alternatives above & 25 & $6,51 \%$ \\
medicines? & & \\
\hline Headache & $152 *$ & $39,58 \%$ \\
Muscle aches & 114 & $29,68 \%$ \\
Stomach ache & 28 & $7,29 \%$ \\
Nausea & 6 & $1,56 \%$ \\
Allergies & 12 & $3,12 \%$ \\
Flu/cold & 49 & $12,76 \%$ \\
No alternatives above & 23 & $5,98 \%$ \\
\hline Yes & & \\
\hline Noes the medication $u s e d$ always work against the symptoms? & $243 *$ & $63,28 \%$ \\
\hline Sometimes & 6 & $1,56 \%$ \\
\hline
\end{tabular}

*Has a statistical significance $(\mathrm{p}<0.05)$. 
When the pain is strong, when it's weak, I use only the same anador ${ }^{\circledR}$. "These reports reveal that the population's lack of knowledge about medication may be endangering their health, since the patient stops taking the medicine he needs and begins to present a health problem by using a medication that he does not need, thus explaining the ineffectiveness of medicines.

$$
\text { Regarding the number of }
$$
participants who have already self- medicated ("Have you ever bought any medication without a prescription?"), 346 (90.10\%) answered 'yes' and 38 participants (9.89\%) reported 'no' taking medicine without a prescription. Of these 346 individuals, $300 \quad(78.12 \%)$ had already purchased, 45 (11.71\%) prescription drugs and only one participant (0.26\%) abstained from answering this question, as shown in the Table 3.

Table 3. Number of participants who have already self-medicated.

\begin{tabular}{ccc}
\hline Have you ever bought any medication without a prescription? & $\mathbf{N}$ & $\mathbf{\%}$ \\
\hline Yes & $346^{*}$ & $90.10 \%$ \\
No & 38 & $9,89 \%$ \\
\hline If so, the product was for sale: & & \\
\hline Over-the-counter medicines & $300^{*}$ & $78.12 \%$ \\
Prescription drugs & 45 & $11.71 \%$ \\
None & 01 & $0.26 \%$ \\
\hline
\end{tabular}

${ }^{*}$ Has a statistical significance $(\mathrm{p}<0.05)$.

It was not possible to establish an age parameter for self-medication since the forms were applied by random participants, and formed a heterogeneous sample in age group, was not statistically significant.

However, population-based studies on the prevalence, incidence, and factors associated with self-medication are rare. With regard to the influence of age on self-medication, studies cited by Loyola Filho et al. (2002), demonstrate that it is not allowed to establish a consistent pattern of behavior, thus, no association was found between age and medication consumption. In some studies the prevalence was in young people, since the consumption of nonprescription medicines tends to be lower in the older classes, due to the fact that these people present other health problems that require them to use prescription drugs, since there is a greater dependence of medical advice (Helman, 2009). However, the incidence of self-medication is higher in the elderly population, since there has been a linear increase in age, as a result of the socioeconomic development of the country, and that in society the elderly are more exposed to polypharmacy, consuming, on average, two to five medications (Telles Filho et al., 2013). Therefore, it is necessary and relevant to make analyzes of this variable, with more attention, which may be correlated to the use of the internet and various technologies by the young, or the cultural process, by the elders.

\section{Conclusion}

The use of new self-care technologies is not limited to young people, although it still prevails in this population. It was also observed in this study that schooling is not directly related to self-medication. It is still very cultural issue as a way of passing information on non-traditional 
treatments, however, the main motivation for the choice of nonprescription the difficulties encountered in the SUS, poor quality of care and failures in the medical relationship public health service, which are masked by the alternative forms of medication and diagnosis by health organizations, which conceal involuntary or unintentional, the risks that this practice can promote in the health of the population.

\section{Acknowledgments}

To the Municipal Health Secretary of Marabá, for the logistical support to this study achieve.

\section{Conflict of interest statement}

Authors declare that they have no conflict of interests.

\section{References}

Andrade, J. T.; Costa, L. F. A. Medicina Complementar no SUS: práticas integrativas sob a luz da Antropologia médica. Revista de Saúde Social, v. 19, no. 3, p. 497-508, 2010. Available from: <https://www.revistas.usp. br/sausoc/article/viewFile/29665/31537>. Accessed on: Nov. 16, 2016.

Ascari, R. A.; Ferraz, L.; Buss, E.; Rennau, L. R.; Brum, M. L. B. Estratégia saúde da família: automedicação entre os usuários. Revista Uningá Review, v. 18, no. 2, p. 42-47, 2014. Available from: <https://www.master editora.com.br/periodico/20140501_121413 .pdf>. Accessed on: Jun. 03, 2017.

Automedicação. Revista da Associação Médica Brasileira, Editorial, v. 47, no. 4, p. 269-270, 2001. https://doi.org/10.1590/ S0104-42302001000400001

Brasil. National Council of Health. Resolution No. 466, of 12 December 2012. Available from: <http://conselho.saude.gov. br/resolucoes/2012/466_english.pdf $>$.

Accessed on: Jun. 03, 2017.

Caprara, A.; Rodrigues, J.A relação assimétrica médico-paciente: repensando o vínculo terapêutico. Revista Ciência \& Saúde Coletiva, v. 9, no. 1, p. 139-146, 2004.
https://doi.org/10.1590/S1413-8123200 4000100014

Furlan, C. E. F. B. Avaliação da qualidade do atendimento hospitalar: o esperado e o recebido por clientes e acompanhantes. Ribeirão Preto: Escola de Enfermagem de Ribeirão Preto, 2011 (Thesis of doctorat).

Gazeta Mercantil. Conselho Regional de Medicina do Estado de Pernambuco. Antiinflamatórios, mocinhos ou vilões? 2008. Available from: <http://cremepe.org.br/ 2008/03/17/antiinflamatorios-mocinhosou-viloes/>. Accessed On: Jan. 23, 2018.

Helman, C. G. Cultura, saúde e doença. 5. ed. Porto Alegre: Artes Médicas, 2009.

Loyola Filho, A. I.; Uchoa, E.; Guerra, H. L.; Firmo, J. O.A. Prevalência e fatores associados à automedicação: resultados do projeto Bambuí. Revista de Saúde Pública, v. 36, no. 1, p.55-62, 2002. https://doi.org/ 10.1590/S0034-89102002000100009

Menicucci, T. M. G. Implementação da Reforma Sanitária: a formação de uma política. Revista Saúde e Sociedade, v. 15, no. 2 , p. 72-87, 2006. https://doi.org/ 10.1590/S0104-12902006000200008

Pieper, M.; Locatelli, C.; Hölzle, D.; Lizot, T.; Uecker, M. A automedicação com medicamentos analgésicos de venda livre. Anais do XXI Seminário de Iniciação Científica, 2013. Available from: $<$ https://www.publicacoeseventos.unijui.edu .br/index.php/salaoconhecimento/article/vi ew/1956/0>. Accessed on: Jan. 23, 2018.

Pinheiro, M.F., Silva, R. N.; Garcia, J. B.; Rodrigues, F. S. M.; Fornari, J. V.; Barnabé, A. S.; Ferraz, R. R. N.; Helene, R.; Abrão, L. S.; Arçari, D. P. Avaliação transversal do perfil de indivíduos portadores de nível superior praticantes de automedicação. Revista Saúde em Foco, No. 6, p 7-15, 2013. Available from: <http://www.unifia.edu.br/ projetorevista/artigos/saude/saude2012/av aliacao_transversal.pdf >. Accessed in: Jun. 15, 2017.

Rocha, B. V.; Gazim, C. C.; Passeto, C. V.; Simões, J. C. Relação médico-paciente. Curitiba: Faculdade Evangélica do Paraná, 2011, Available from: <http://www.crmpr. org.br/publicacoes/cientificas/index.php/re vista-do-medico-residente/article/viewFile/ 8/13>. Accessed on: Nov. 16, 2016.

Telles Filho, P.C. P.; Almeida, Pena, A. G. P.; Pinheiro, M. L. P. Automedicação em idosos: 
um problema de saúde pública. Revista de Enfermagem da UERJ, v. 21, No. 2, p. 197-201, 2013. https://doi.org/10.12957/ reuerj.2013.7107

Vasconcellos-Silva P. R.; Castiel, L. D. As novas tecnologias de autocuidado e os riscos do autodiagnóstico pela Internet. Revista Panamericana de Salud Pública, v. 26, No. 2, p.172-175, 2009. Available from: <https://www.scielosp.org/article/rpsp/200 9.v26n2/172-175/>. Accessed on: Apr. 01, 2018. 